\title{
INCREASING SAFETY BELT USE IN A SECONDARY ENFORCEMENT STATE: EVALUATION OF A THREE-COUNTY SPECIAL ENFORCEMENT PROGRAM
}

\author{
Fredrick M. StrefF, Lisa J. Molnar, and Carl Christoff \\ The University of Michigan, Transportation Research Institute, Ann Arbor, \\ MI 48109, U.S.A.
}

(Received 11 March 1991; in revised form 10 July 1991)

\begin{abstract}
Special enforcement programs to increase belt use present a unique challenge in states with secondary enforcement laws. This paper reports findings from an evaluation of a combined public information and education/enforcement program to increase restraint use along a highly traveled corridor in three Michigan counties. This program (US-31 SAVE) was successful in increasing belt use at least temporarily along the special enforcement corridor. Observed belt use increased from a baseline rate of $56.7 \%$ to $65.1 \%$ during the program before slipping slightly to $62.7 \%$ after the intensive enforcement and PI\&E declined (all differences significant at $p<.05$ ). This paper details program and evaluation activities and suggests future research needs to better understand the most effective mix of public information and enforcement efforts in states with secondary belt use laws.
\end{abstract}

\section{INTRODUCTION}

Despite the efficacy of automobile safety belts in reducing crash-related injury, belt use remains low in the United States. Mandatory belt use laws have been passed in 37 states and the District of Columbia to increase belt use, but more than $50 \%$ of motorists still travel unrestrained (Datta and Guzek 1990). Despite the modest success of belt laws for promoting belt use, these laws have proven effective in reducing deaths and injuries from traffic crashes (e.g. Campbell, Stewart, and Reinfurt 1991; Reinfurt, Campbell, Stewart, and Stutts 1990; Streff, Wagenaar, and Schultz 1990.) The National Highway Traffic Safety Administration (NHTSA) considers promotion of safety belt use to be one of the highest priority highway safety program activities within the agency and has conducted and promoted a variety of programs designed to increase belt use. Special emphasis has been placed on the development, implementation, and evaluation of innovative programs that involve law enforcement agencies and build community support for efforts to raise levels of belt law compliance.

Campbell (1988) demonstrated that belt use in the United States is related to both the enforcement activity permitted under law (i.e. primary vs. secondary enforcement) and actual enforcement rigor as measured by annual belt citation rates per 100,000 population. Despite the demonstrated efficacy of primary enforcement, Michigan law permits only secondary enforcement of safety belt nonuse. In Michigan, vehicles cannot be pulled over and occupants cited solely for safety belt nonuse. Instead, the vehicle must be pulled over for some other reason before officers may issue citations for safety belt nonuse. One important reason given for passing the law as a secondary offense in Michigan was the potential for police to abuse the belt use law and harass nonwhites. It was pointed out in legislative discussions that because the average belt use rate of nonwhites is lower than that of whites, there was the potential for abuse of the intent of the belt law. This concern was sufficient to convince legislators to permit only secondary enforcement of the law.

While combined enforcement and public information and education (PI\&E) campaigns have proven successful in increasing safety belt use in primary enforcement states (e.g. Rood, Kraichy, and Carman 1987; Williams, Preusser, Blomberg, and Lund 1987), the application of similar programs in secondary belt law states must differ somewhat. The stepped-up enforcement can focus on increased diligence of police officers in citing 
vehicle occupants observed not using safety belts once they have been pulled over. The program may emphasize increased enforcement of some other section of the vehicle code that would permit increased traffic stops, thus providing more opportunities for safety belt law enforcement, or some combination of these approaches may be applied. The US-31 Shoreline Area Vehicle Enforcement (US-31 SAVE) program applied the combination approach to increase enforcement of speeding and other moving violations as well as stepped-up enforcement of Michigan's restraint laws subsequent to traffic stops.

US 31, a major state trunk line in western Michigan, is one of the main commuter routes connecting the cities of South Haven, Holland, Grand Haven, and Muskegon with the northern counties of the state, and also carries seasonal traffic from points south to areas in western Michigan for business and recreation. US 31 is the main connector highway for all communities along the western shore of Lake Michigan. The large variety and number of business and popular recreational attractions along the lake make US 31 a busy, often congested, and sometimes dangerous roadway.

The US-31 SAVE program combined heightened enforcement with public information and education (PI\&E) campaigns in three counties in Michigan. It represented a cooperative effort among two western Michigan State Police posts; county sheriff's departments in Allegan, Ottawa, and Muskegon Counties; and city police departments in Holland and Grand Haven. This program was intended to reduce crash and injury rates on US 31 by increasing awareness of speed and occupant restraint use laws and increasing enforcement of these laws. The US-31 SAVE program was innovative in that it was planned to increase safety belt use by applying the strategy of increased enforcement and public information in a state with a secondary enforcement belt law through the cooperative efforts of seven police agencies across three counties.

\section{US-31 SAVE PROGRAM IMPLEMENTATION}

All agencies involved in the program provided selective enforcement patrols along US 31 within their jurisdictions, trying to ensure that those periods of the day when traffic problems were at their peak were covered. Selective enforcement patrols included vehicles that were fully marked and identified as police vehicles to maximize visibility of the enforcement effort. Bimonthly meetings involving representatives of each of the participating police agencies were held to coordinate program activities.

The US-31 SAVE program began its activities with an official media "kick-off" on October 23, 1989. While the program continued beyond September 1990, enforcement activities associated with the program were curtailed between October 1990 and December 1990 because of budgetary constraints associated with the Federal budget crisis.

\section{Patrol activity}

Police patrol activities related to the US-31 SAVE program were recorded by each agency involved in the program and reported monthly. Hours devoted to patrol activities for the US-31 SAVE program each month are described in Fig. 1. Overall patrol activity increased fourfold in the first full month of program activities, increasing gradually to a peak in May, and declining thereafter. However, there is a noticeable peak in September coincident with the end of the Michigan Office of Highway Safety Planning (OHSP) grant period. It is likely that police agencies had spent their patrol resources more conservatively than anticipated prior to the end of the grant period and the jump in September was due in large part to an attempt to "clear the books" at the end of the grant period, September 30.

\section{Enforcement activity}

Enforcement actions taken by police during their patrol activities for the US-31 SAVE program are described in Figures 2-4. Figure 2 shows the total number of speeding citations issued in the three counties. This figure shows that the number of speeding 


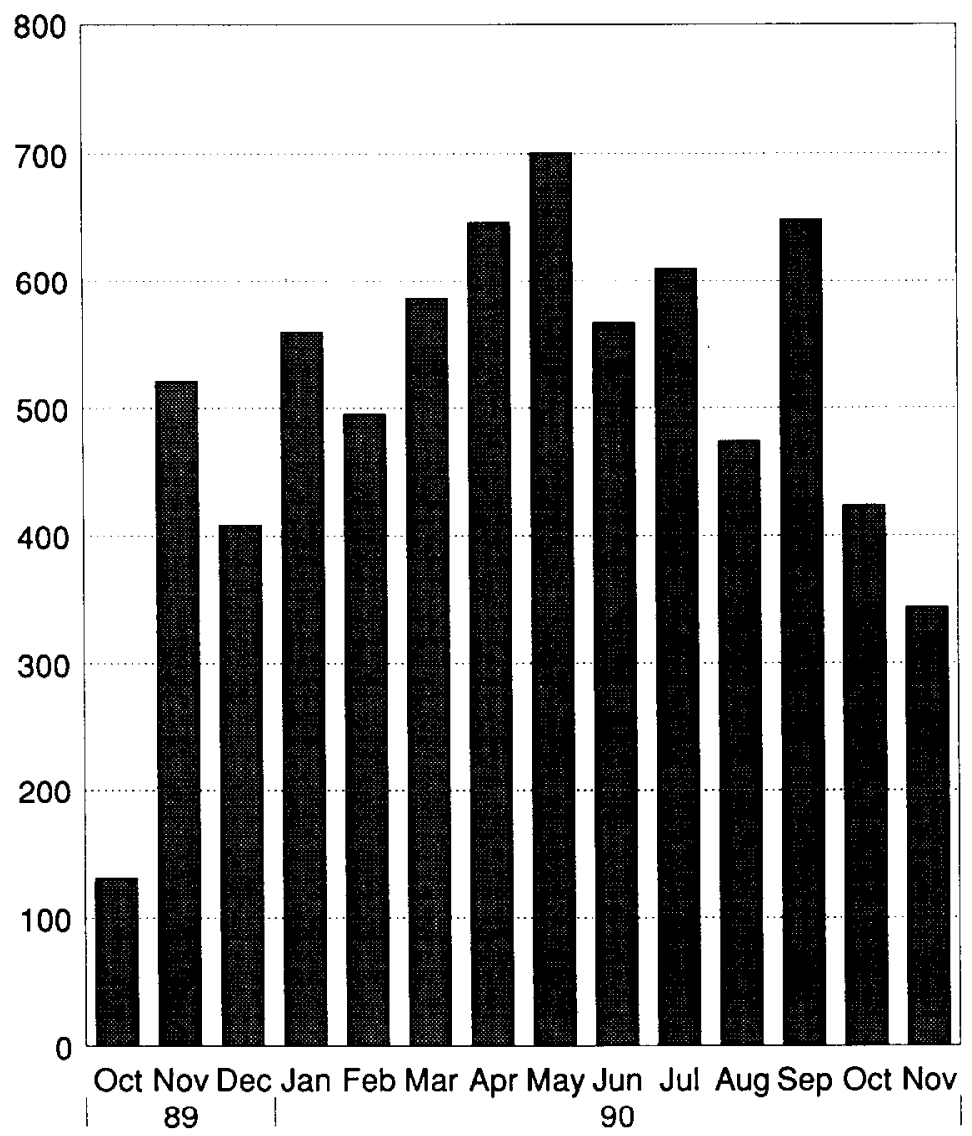

Fig. 1. Police patrol hours on US 31.

citations roughly mirrors patrol hours with a noticeable peak in November, just after the program began, peaking again in May and July. The number of speeding citations dropped back to preprogram levels in October and November of 1990 (the postprogram period of low enforcement activity).

Figure 3 shows the number of citations and verbal warnings issued to motorists for safety belt nonuse. Recall that before a motorist could be issued either a citation or warning for belt nonuse, he/she first had to be stopped for some other reason, such as speeding. As can be seen in the figure, citations for belt nonuse were issued more frequently than verbal warnings. This is a positive sign of the importance placed on safety belt nonuse by officers in the field. It is also interesting that the proportion of warnings to citations remains fairly consistent throughout the program period, indicating there were not periods of exceptional strictness or leniency on issuing safety belt nonuse citations. As was the case for speeding citations, the number of safety belt citations and warnings roughly followed the pattern of patrol activity.

The number of safety belt citations and warnings issued per 100 speeding citations is shown in Fig. 4. This figure peaked in February (nearly 60 belt citations per 100 speeding) and remained around 40-45 belt citations per 100 speeding citations in March through June before dropping off in July.

\section{US-31 public information and education (PI\&E) efforts}

All police agencics worked with the ncws media, including local newspapers, TV, and radio stations, to promote the US-31 SAVE program. During the course of the program three press releases were distributed describing the program and its successes to date. A local clipping service was employed to collect all newspaper articles related to US-31 published in the media market served by US 31. Figure 5 depicts the number 


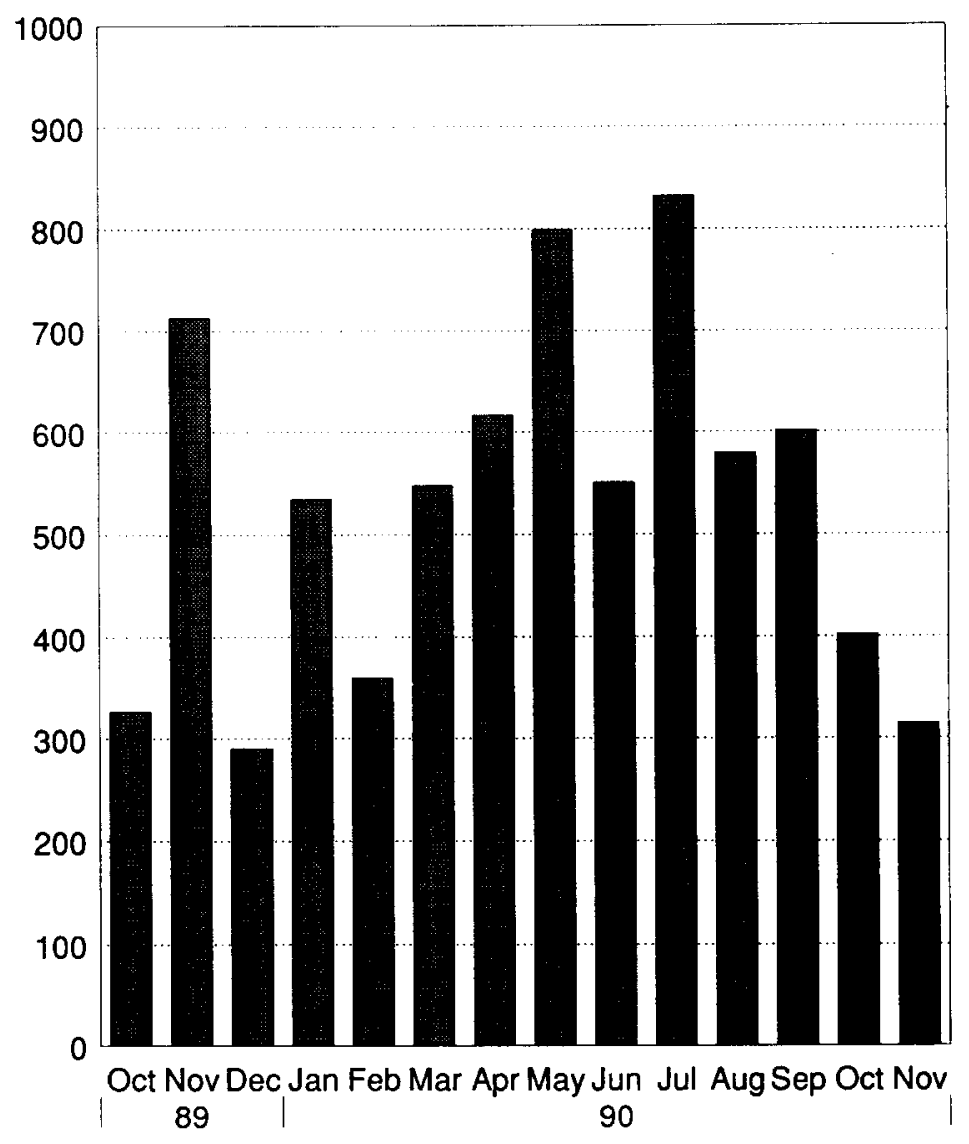

Fig. 2. Speeding citations issued on US-31 SAVE patrol.

of articles in which at least part of the article was devoted to a description of some aspect of the US-31 SAVE program and the number of column inches that described US-31 activities in these articles. Column inches were calculated including headline and photographs related to the article. A standard of 2-inch wide columns was used for the calculations. For example, a 5 -inch long article in a 2 -inch wide column yields 10 column inches. For articles that used columns of width other than 2 inches, the column width was normalized in calculations to 2 inches. Some articles described the US-31 SAVE program in only one small part of a larger story. In these cases, only the portion of the story related to the US-31 SAVE program was included in the column length calculations.

It was prohibitively costly to monitor radio and TV broadcasts to determine PI\&E efforts using broadcast media. Police agencies were encouraged to regularly collect media contacts using a media log. Unfortunately, such logs were not maintained, and thus we are unable to accurately document broadcast media participation and support for the program. However, program personnel reported that broadcast media did support the program.

A wide variety of other PI\&E efforts were undertaken to publicize the program. The Michigan Department of Transportation installed several large 4-by-8-foot signs along the highway to identify the section of US 31 from the town of South Haven to the town of Muskegon as a selective enforcement zone. The signs displayed large Michigan State Police, sheriff's department, and municipal police department shields. The signs advised the public that they were passing through an area patrolled by the US-31 SAVE enforcement team. In addition, four large banners were hung on a variety of overpasses and buildings during periods when festivals and other events occurred announcing the program to event attendants. 


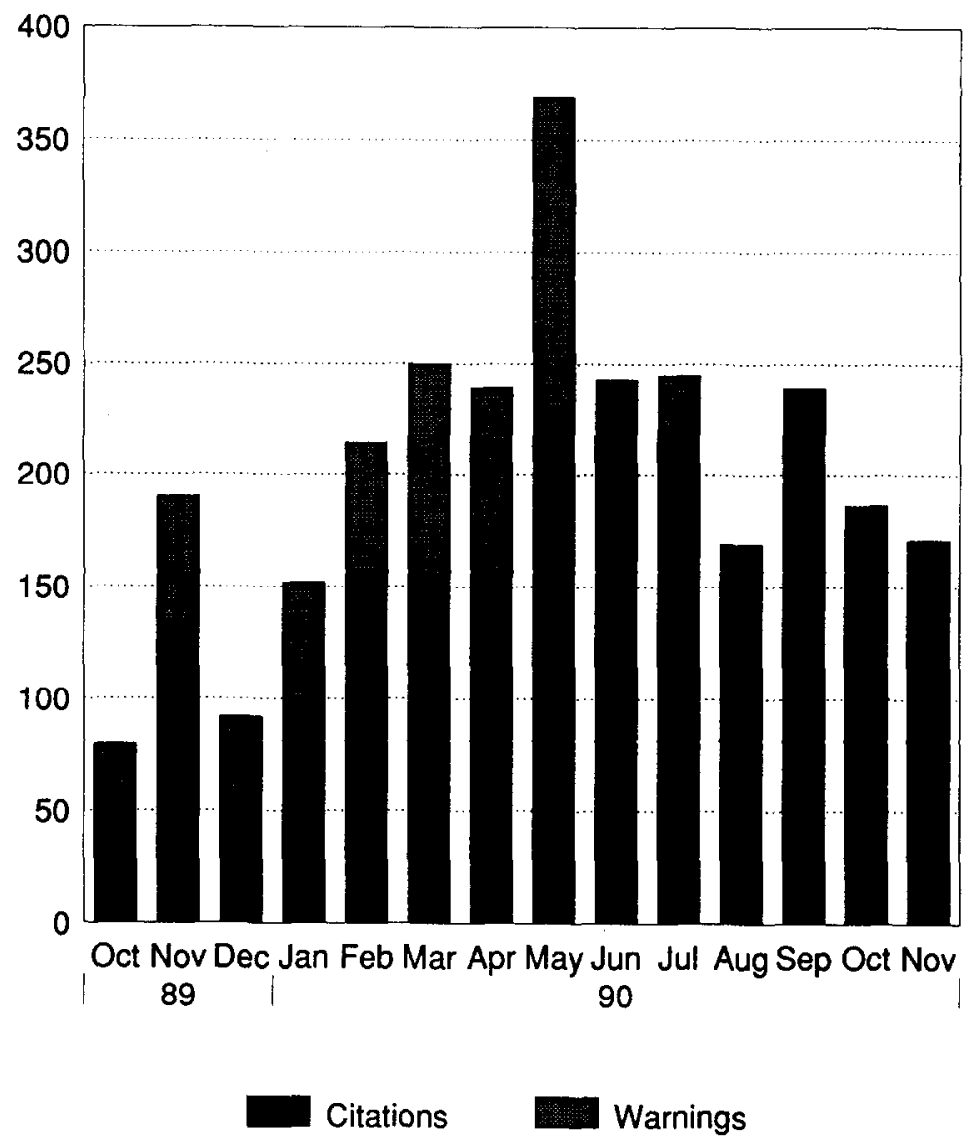

Fig. 3. Safety belt nonuse citations and verbal warnings issued on US-31 SAVE patrol.

The town of Holland Police Department acted as the principal agency for all printed public information and education material that was developed for the US-31 SAVE program. All agencies involved in the program had equal access to the printed materials produced. The following materials were produced and distributed: 20,000 flyers distributed to persons stopped for violations on US 31; 250 large posters announcing and describing the US-31 SAVE program distributed for display by interested businesses along the US-31 corridor; 5008.5 inch by 11 inch posters announcing and describing the US-31 SAVE program distributed for display by interested businesses along the US-31 corridor; 10,000 US-31 SAVE stickers distributed by officers in the field and at police stations; 5,000 US-31 SAVE key rings distributed by officers in the field and at police stations; 50,000 US-31 SAVE car trash bags distributed at festivals and other events; 100,000 US-31 placemats distributed to restaurants along the US-31 corridor.

\section{EVALUATION METHODS}

\section{Design}

The basic experimental design used to evaluate the US-31 SAVE program was a multiple time-series design. Although the US-31 SAVE program continued beyond September 1990 , the stepped-up enforcement involved in the program was halted temporarily due to the Federal budget crisis in the fall, permitting a time-series reversal design. That is, collection of preprogram baseline data (i.e. September 1989), intervention data (November through September 1990), and withdrawal data (October through December 1990). In a reversal design, an intervention is said to have had an effect if there is a change in dependent variables detected between baseline and intervention periods. A 


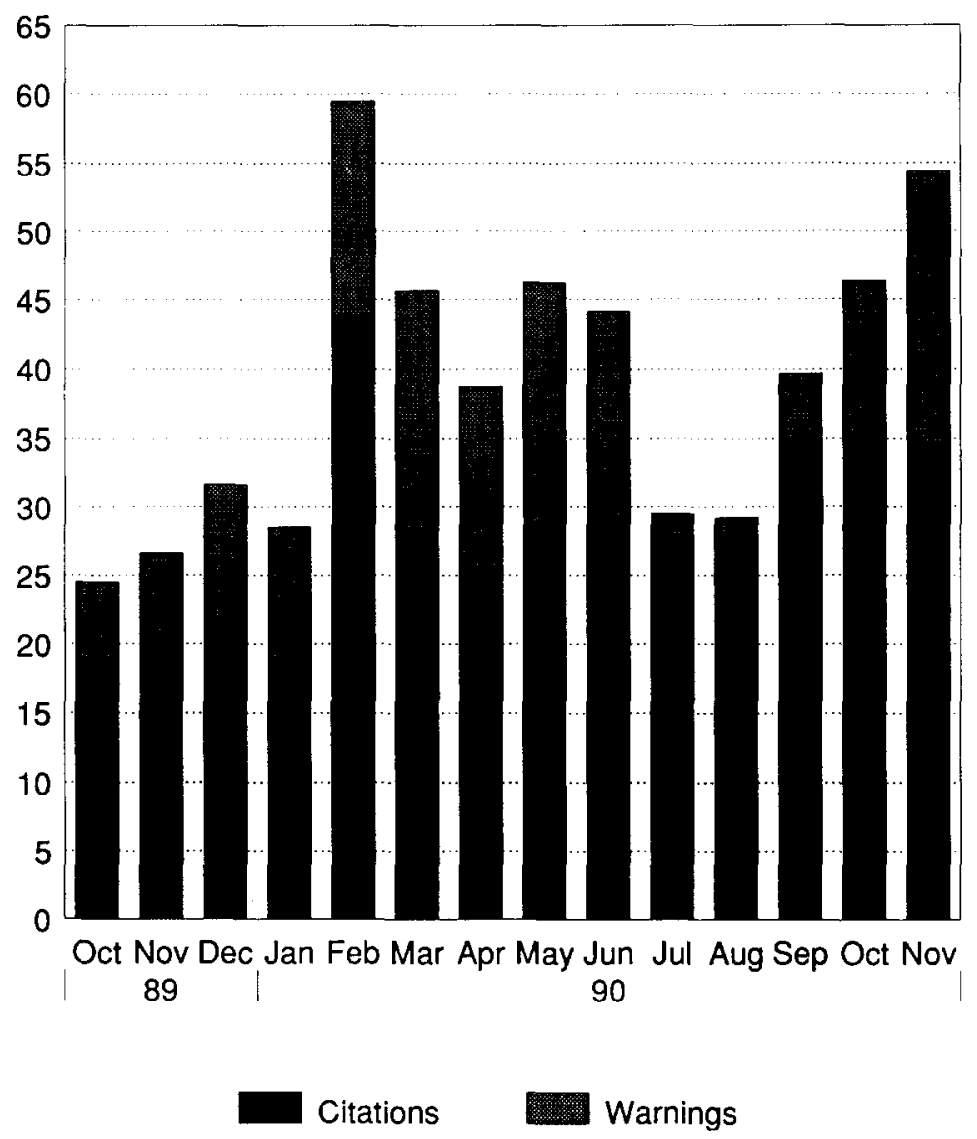

Fig. 4. Safety belt citations and verbal warnings per 100 speed citations.

control to determine if the intervention was responsible for any observed changes in the dependent variables is provided in the reversal (withdrawal) period. A conclusion that the intervention caused any observed changes is strengthened by a return to baseline in the dependent variables during the reversal period. While it is generally desirable for there to be no reversal in intervention effects even after an intervention has been withdrawn, it is often the case (especially in safety belt promotion programs) that there is a return toward baseline levels in the withdrawal period but these levels typically do not return fully to baseline.

In addition to the time-series reversal design, we had belt use data available from statewide safety belt observations that have been conducted regularly since 1984 (Wagenaar and Wiviott 1986; Streff and Molnar 1990). Belt usc patterns in these data were compared to data collected along US 31 to provide an additional control group against which to compare US-31 SAVE program effects. Although this control procedure is less than perfect because of the inability to truly control safety belt promotional activities in all sites, this group was instructive in determining if changes in belt use along US 31 reflected more general statewide patterns.

\section{Dependent variable: Occupant restraint use}

Observation site selection. A carefully selected set of observation sites was used to sample motorists traveling on US 31 in Allegan, Muskegon, and Ottawa Counties during daylight hours. The goal of the sample design was to minimize measurement error, using sites where observations could be made efficiently and economically. Observation sites were limited to intersections with three-color cycling traffic signals or stop signs to allow adequate time for observers to record safety belt data. A total of 15 observation sites were selected for the restraint use observations. 


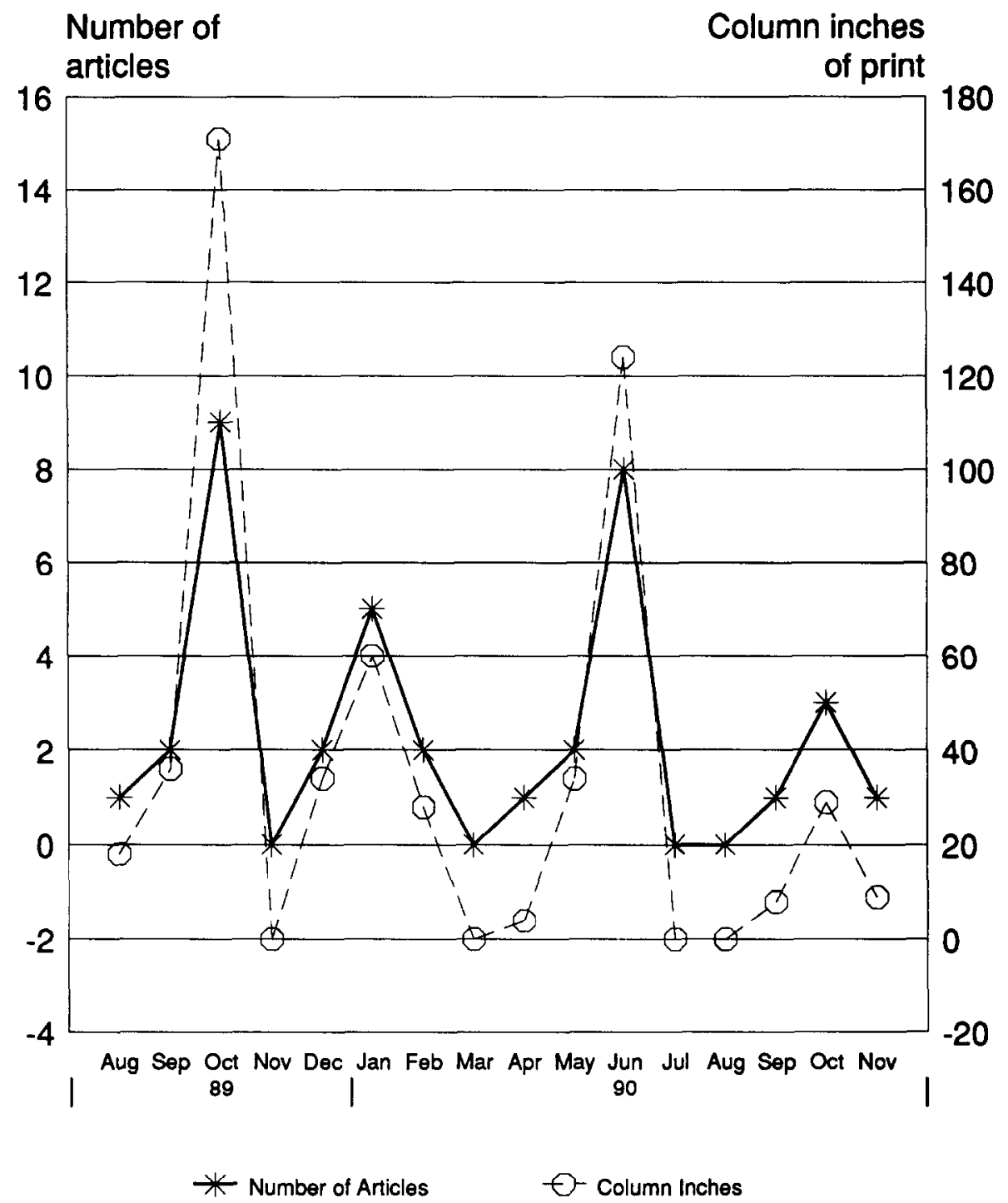

Fig. 5. Number of articles and column inches of print describing US-31 SAVE activities.

Detailed maps of the three counties and lists of all intersections on US 31 with three-color cycling traffic signals and stop signs were obtained from the Michigan Department of Transportation. Thirty-five such intersections were identified and highlighted on the maps. Sixteen of these intersections were signalized. The remaining 19 intersections had stop signs. In selecting observation sites, we wanted to ensure that intersections in each county and more particularly each police jurisdiction involved in the US-31 SAVE program would be represented. Although sites needed to be distributed along the entire stretch of US 31 within the three-county area, site selection also needed to account for areas of greater population density such as Holland and Grand Haven. Therefore, six of the 15 sites were located within the limits of these cities. Because the section of US 31 under study contains some segments that are limited access and some that are not, observation sites included both local intersections and freeway off-ramps.

Observation methods. Observations were limited to drivers and front-right seat passengers of passenger cars, vans, and light trucks. Occupants of ambulances, buses, specialized vehicles, and medium and heavy trucks were not observed because they are either exempt from the provisions of Michigan's restraint laws or vehicle type makes accurate restraint use observation prohibitively difficult. Observations were limited to 
daylight hours for accurate observation of restraint use. The distribution of observations by time of day and day of week reflected the relative emphasis of the US-31 SAVE program to the extent possible. Observations were conducted more frequently in the summer months when enforcement activities were expected to be at their peak. Observations were conducted prior to the evaluation grant award in September 1989 and after the evaluation grant award in April, June, early and mid-July, August, October, and December 1990.

Each sampled intersection was visited by two specially trained field staff (the field observer/supervisor and one field observer): one observed traffic northbound on US 31 and the other observed traffic southbound on US 31. Each observed a sample of 54 vehicles during a preselected 45 -minute period. ${ }^{*}$ At signalized intersections, observers limited the number of vehicles recorded during any given traffic signal cycle to three. This procedure was adopted because surveys of restraint use conducted since implementation of Michigan's mandatory safety belt law indicate that motorists in long traffic queues may buckle up after noticing an observer examining vehicles ahead of them in the queue.

Observation forms. Observers recorded information on restraint use, estimated age, and gender for each driver and front-right passenger of sampled vehicles on precoded vehicle forms. Observers also recorded whether vehicles had Michigan license plates or out-of-state license plates. Observers also recorded site number, site type (intersection or freeway exit ramp), date, time of day, and day of week. The forms had a comments section, and observers were encouraged to record comments about each site related to traffic flow and unusual characteristics of the site.

Observer training and data collection. All field personnel participated in extensive training sessions that included review of data collection policies and procedures and practice field observations. Novice observers spent two days at preselected sites, including signalized intersections and freeway exit ramps, practicing observation techniques and field procedures. After each practice session, observers met with the field data coordinator to discuss problems that had occurred. Interobserver reliability was monitored prior to actual data collection through a formal checking process and was found to be near or above $90 \%$ for all variables.

\section{RESULTS}

\section{Effects on observed restraint use}

Overall restraint use (safety belt use of drivers and front-right seat passengers) increased during the US-31 program from baseline levels and then partially declined during the last two observation periods (Fig. 6). Baseline observations (conducted in September 1989) found overall restraint use to be 56.7\%. In April 1990, restraint use was observed at essentially the same level $(56.2 \%)$. Observations made two months later in June 1990 showed an increase in restraint use to $65.1 \%$. The upward trend continued during the next two observation periods in mid- and late July with restraint use reaching $66.0 \%$ and $68.8 \%$, respectively. In August 1990, restraint use remained over $67 \%$. Restraint use calculated over the entire intervention period (using observations from April through August 1990 ) was $65.1 \%$. This belt use rate is significantly higher than the baseline rate of $56.7 \%$ recorded in September $1989(z=6.22, p<.05)$. Overall restraint use was found to have decreased slightly in October and December from the summer peak to $62.7 \%(z=2.31, p<.05)$. Although there was a decline in restraint use during this withdrawal period, restraint use remained higher during this period than the baseline period $(z=3.86, p<.05)$. These findings show that the US-31 SAVE program was successful in increasing restraint use by drivers and passengers traveling the US-31 corridor.

The trends in restraint use among age and gender subgroups were quite similar to the pattern of restraint use for the total sample (Table 1). Although month to month

*At a few sites, observers were not able to collect data for the full complement of 54 vehicles because of low traffic volume. 


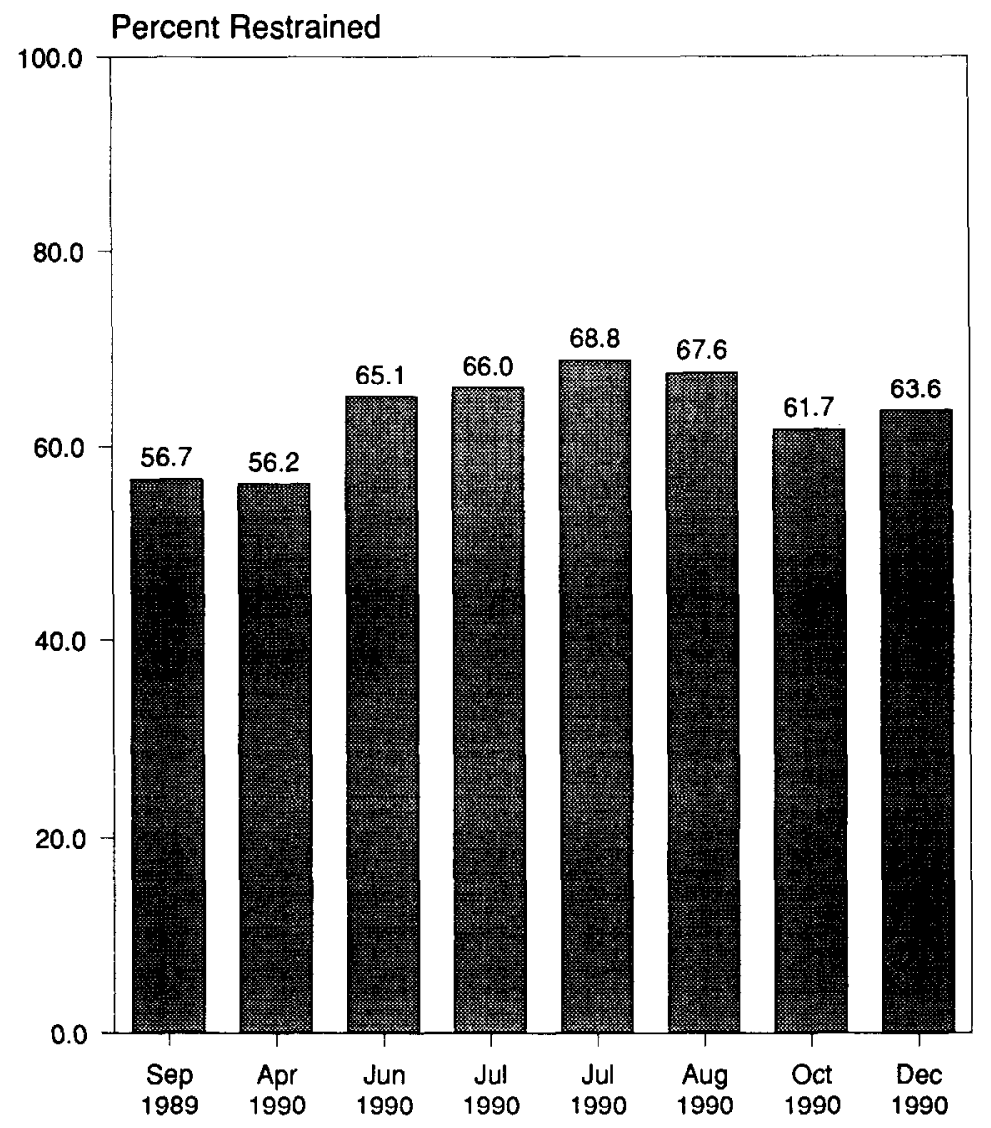

Fig. 6. Overall restraint use at US-31 observation sites.

changes varied across these subgroups, in general, restraint use increased after April 1990 , peaked in late July or August 1990, and then began to partially decline for all subgroups.

Because the US-31 SAVE program represented a coordinated effort among several police agencies in different jurisdictions, we focussed primarily on restraint use for the total program area. However, we also examined restraint use by county to identify

Table 1. Percent restraint use by survey period, gender, and age

\begin{tabular}{|c|c|c|c|c|c|c|c|c|}
\hline & $\begin{array}{c}\text { SEPT } \\
1989\end{array}$ & $\begin{array}{c}\text { APRIL } \\
1990 \\
\end{array}$ & $\begin{array}{c}\text { JUNE } \\
1990\end{array}$ & $\begin{array}{c}\text { JULY* }^{*} \\
1990 \\
\end{array}$ & \begin{tabular}{|c} 
JULY* \\
1990 \\
\end{tabular} & $\begin{array}{l}\text { AUG } \\
1990\end{array}$ & $\begin{array}{l}\text { OCT } \\
1990\end{array}$ & $\begin{array}{l}\text { DEC } \\
1990 \\
\end{array}$ \\
\hline \multicolumn{9}{|l|}{ GENDER } \\
\hline Male & & 460 & 606 & 509 & 632 & 601 & 577 & 507 \\
\hline Total N & $\begin{array}{l}31.1 \\
816\end{array}$ & $\begin{array}{r}40.9 \\
742\end{array}$ & 784 & 823 & 899 & 915 & 751 & 702 \\
\hline Female & & & & & & & & \\
\hline $\begin{array}{l}\text { \% restrained } \\
\text { Total N }\end{array}$ & $\begin{array}{r}63.3 \\
687\end{array}$ & $\begin{array}{r}67.0 \\
631\end{array}$ & $\begin{array}{r}70.1 \\
718\end{array}$ & $\begin{array}{r}72.0 \\
825\end{array}$ & $\begin{array}{r}74.8 \\
853\end{array}$ & $\begin{array}{r}75.9 \\
828\end{array}$ & $\begin{array}{r}66.0 \\
715\end{array}$ & $\begin{array}{r}67.5 \\
725\end{array}$ \\
\hline \\
\hline $0-3$ & & & & & & & & \\
\hline$\%$ res & 75.0 & 100.0 & 80.0 & 36.4 & 75.0 & 100.0 & 60.0 & 100.0 \\
\hline $4-15^{\text {Total N }}$ & 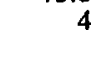 & & 10 & 11 & 0 & & 5 & 10 \\
\hline \% restrained & 53.3 & 50.0 & 57.6 & 55.0 & 78.4 & 65.6 & 40.0 & 73.1 \\
\hline $\begin{array}{l}\text { Total N } \\
16-29\end{array}$ & 30 & 48 & 66 & 60 & 51 & 61 & 35 & 26 \\
\hline \% restrained & 41.2 & 51.1 & 54.5 & 59.1 & 57.8 & 62.2 & 52.8 & 52.5 \\
\hline $\begin{array}{l}\text { Total N } \\
30-59\end{array}$ & 362 & 370 & 380 & 447 & 517 & 505 & 434 & 398 \\
\hline$\%$ restrained & 58.4 & 55.8 & 68.3 & 69.7 & 72.2 & 67.2 & 65.7 & 66.5 \\
\hline $60+{ }^{\text {Total N }}$ & 741 & 683 & 800 & 832 & 879 & 870 & 790 & 809 \\
\hline $\begin{array}{l}\text { \% restrained } \\
\text { Total N }\end{array}$ & $\begin{array}{r}68.6 \\
366\end{array}$ & $\begin{array}{r}64.4 \\
267\end{array}$ & $\begin{array}{r}72.8 \\
246\end{array}$ & $\begin{array}{r}69.1 \\
298\end{array}$ & $\begin{array}{l}76.1 \\
297\end{array}$ & $\begin{array}{r}77.3 \\
299\end{array}$ & $\begin{array}{r}69.3 \\
202\end{array}$ & $\begin{array}{l}71.7 \\
184\end{array}$ \\
\hline
\end{tabular}

*Two sets of observations were conducted in July 1990. 
possible deviations from the overall trend. County specific changes in restraint use generally followed the overall pattern with Muskegon County experiencing the largest decline in use rates in October 1990. However, enforcement activities in Muskegon County were more inconsistent throughout the entire study period and were subject to greater disruption between October and December 1990 than in the other two counties.

\section{DISCUSSION}

The US-31 SAVE program seems to have been at least temporarily effective in achieving its goal of increased restraint use along the US-31 corridor in Allegan, Uttawa, and Muskegon counties. Restraint use increased at the same time as US-31 SAVE program efforts began in earnest, however these use rates declined again when enforcement activities declined in October 1990. This suggests that the program caused the belt use increase, but that continued active enforcement may be required to maintain high belt use levels. To better understand whether the observed effects along US 31 were due to the US-31 SAVE program itself or if these changes were part of a more general statewide trend, we compared the changes in restraint use along US 31 to patterns in restraint use observed at other locations in the state.

While it may be the case that some of the observed US-31 SAVE effects were part of a more general statewide trend, we do not believe all of the observed effects were due to such a trend. First, we found a significant increase in restraint use coincident with the implementation of the US-31 SAVE program and a subsequent slip in restraint use coincident with a reduction of US-31 SAVE enforcement activities. This evidence supports the contention that the US-31 SAVE program, and not some other phenomenon

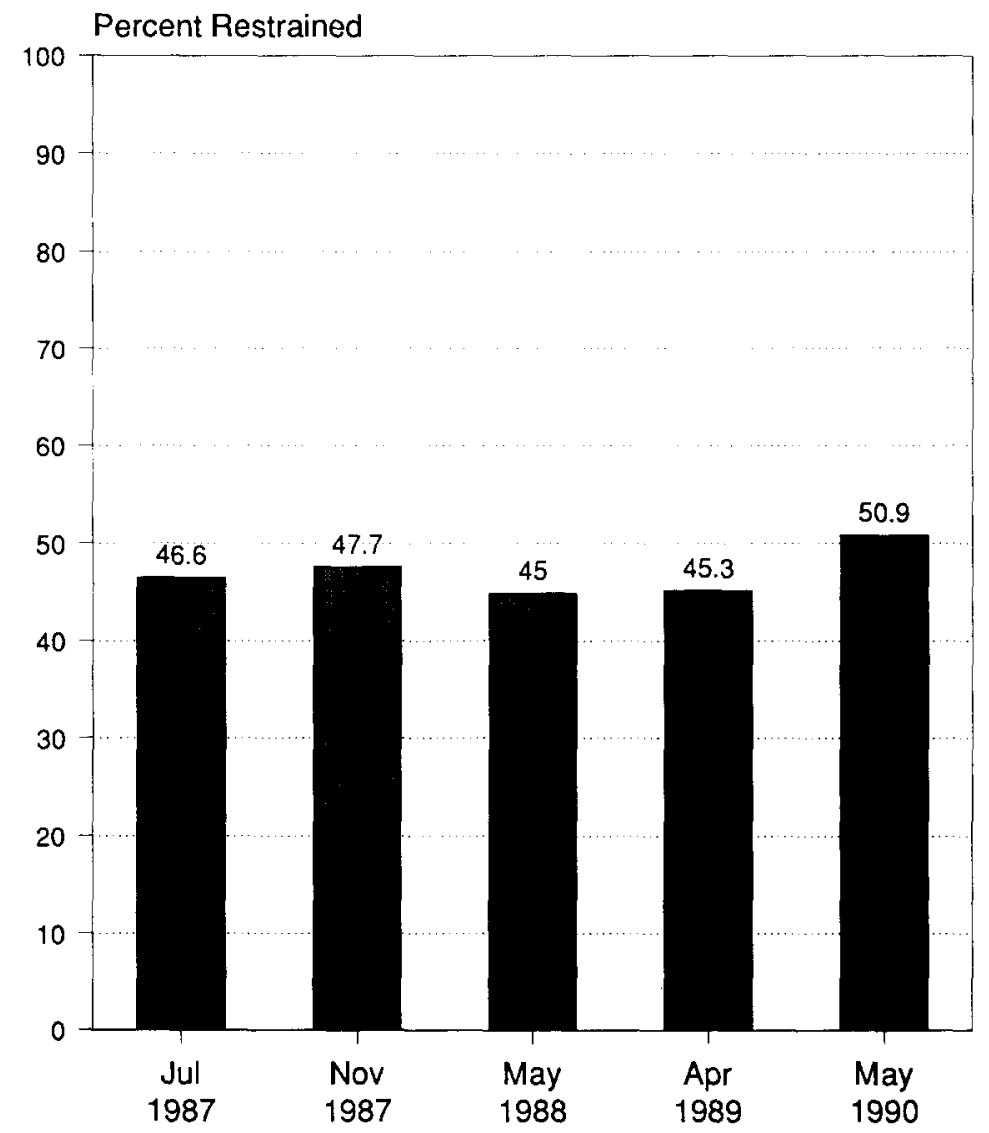

Fig. 7. Restraint use from statewide observation surveys. 
or trend, was responsible for the increased restraint use. In addition, we examined restraint use gathered from observations at 234 sites throughout Michigan conducted in July and November 1987, May 1988, April 1989, and May 1990 as part of an ongoing program to study restraint use in the state as a whole. Two of these 234 sites were also part of the US-31 SAVE observation site set.

Observations made as part of the statewide restraint use study found a significant increase in May 1990 from an average of $46.1 \%$ during the July 1987 through April 1989 period to $50.9 \%$ in the May 1990 observation wave. The May 1990 restraint use rate was the first statistically significant increase in restraint use observed in Michigan since the implementation of the adult restraint use law in July 1985 (Fig. 7). This result suggests that some of the effects observed on US 31 may have been due to changes in statewide restraint use patterns rather than the US-31 SAVE program. However, our confidence that the US-31 SAVE program was effective in increasing restraint use is strengthened when we compare the increase in restraint use observed in the state as a whole to the increase observed at two US-31 SAVE sites that were also part of the regular statewide surveys.

Over the July 1987 through April 1989 period, restraint use at the two statewide survey sites along the US-31 SAVE corridor averaged $49.8 \%$, never exceeding $54.5 \%$ (Fig. 8). In the May 1990 observation wave, restraint use was $64.5 \%, 14.7$ percentage points higher than average restraint use in the previous period. In the state as a whole, restraint use was only 4.8 percentage points higher in May 1990 than the average in the July 1987 through April 1989 period. Thus, we may conclude that while there may have been a positive effect on restraint use due to several other programs across the state

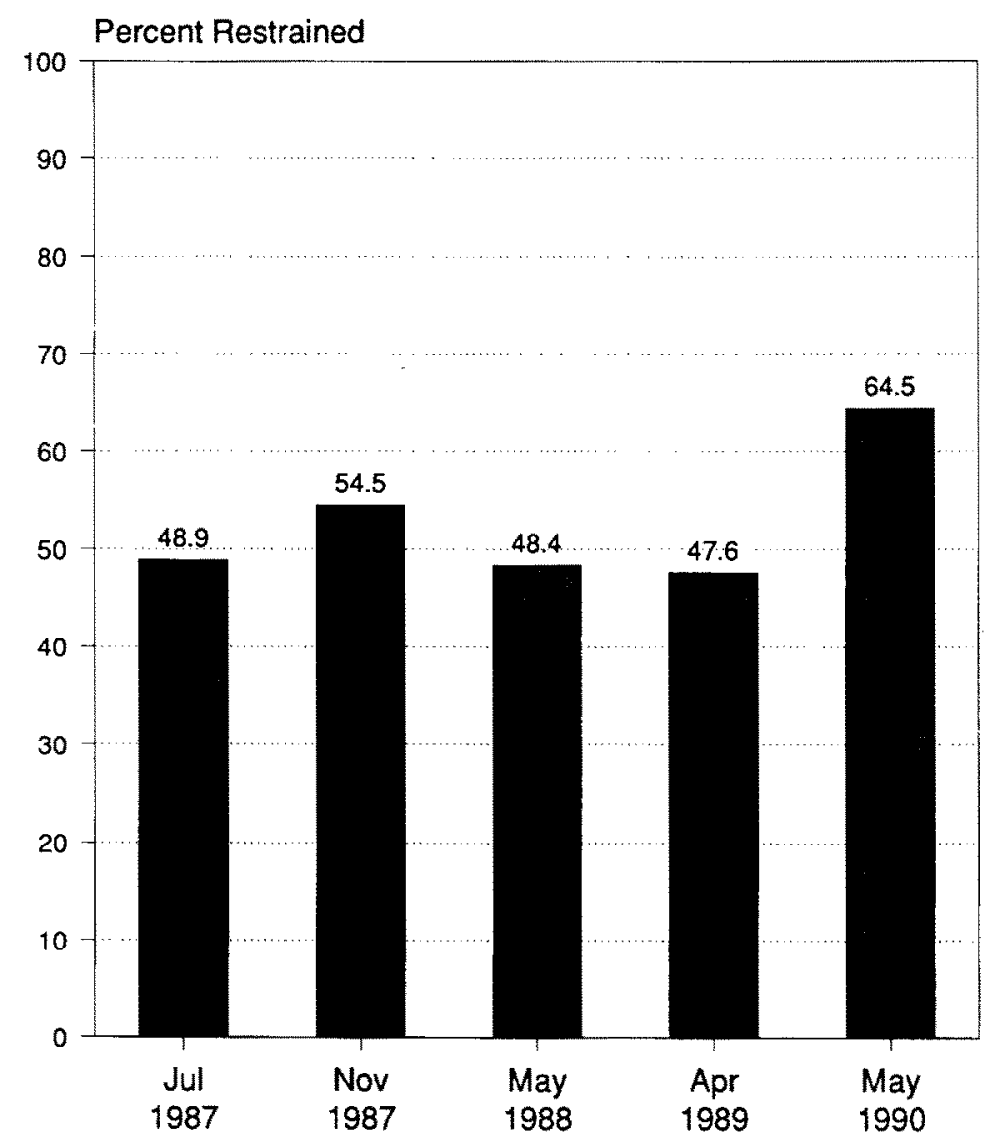

Fig. 8. Restraint use from statewide observation surveys-sites along the also-used US-31 SAVE corridor. 
which contributed to the success of the US-31 SAVE program, the program itself was likely the major factor causing restraint use to increase along US 31 .

It is possible that the observed increase was due to seasonal effects rather than or in addition to effects of the US-31 SAVE program, given that restraint use increased in June 1990 and decreased again in the fall. This does not appear to be the case. Reexamination of Figs. 7 and 8 show that restraint use is relatively stable across the months of the year. In fact, restraint use was higher in the November 1987 observation wave than in any of the other waves (with the notable exception of the May 1990 wave). It can therefore be concluded that observed increases in restraint use can be ascribed to the US-31 SAVE program and not to seasonal effects.

An argument has been made that the US-31 SAVE program was successful in its goal to increase restraint use along the US-31 corridor targeted by the program (at least while enforcement was rigorous and visible). Given this success, it is valuable to better understand how the US-31 SAVE program achieved this success. An understanding of how these effects were achieved may help future programs target resources more efficiently.

The US-31 SAVE program had two basic components, PI\&E and enforcement. While it is difficult to measure the behavioral effects of distributing litter bags, posters, and other promotional and educational materials, we did attempt to determine if there was any relationship between the number and length of newspaper articles related to US-31 and restraint use. We charted restraint use together with the number and length of articles related to the US-31 SAVE program to examine possible relationships (Figs. 9 and 10). No systematic relationship between restraint use and newspaper coverage is evident from the charts. Although restraint use increased along with newspaper coverage in June 1990, such coverage prior to that point seemed to have had little effect on restraint use. No attempt was made to determine public awareness of the US-31 SAVE program or its educational goals, so we cannot comment on the effectiveness of PI\&E efforts to educate the public or inform them of the stepped-up enforcement activities.

The need for effective media coverage of enforcement programs was well documented by Rood, Kraichy, and Carman (1987). Their evaluation of a restraint use enforcement program in the State of New York showed that in a community where restraint nonuse citations doubled without an accompanying media campaign, no change
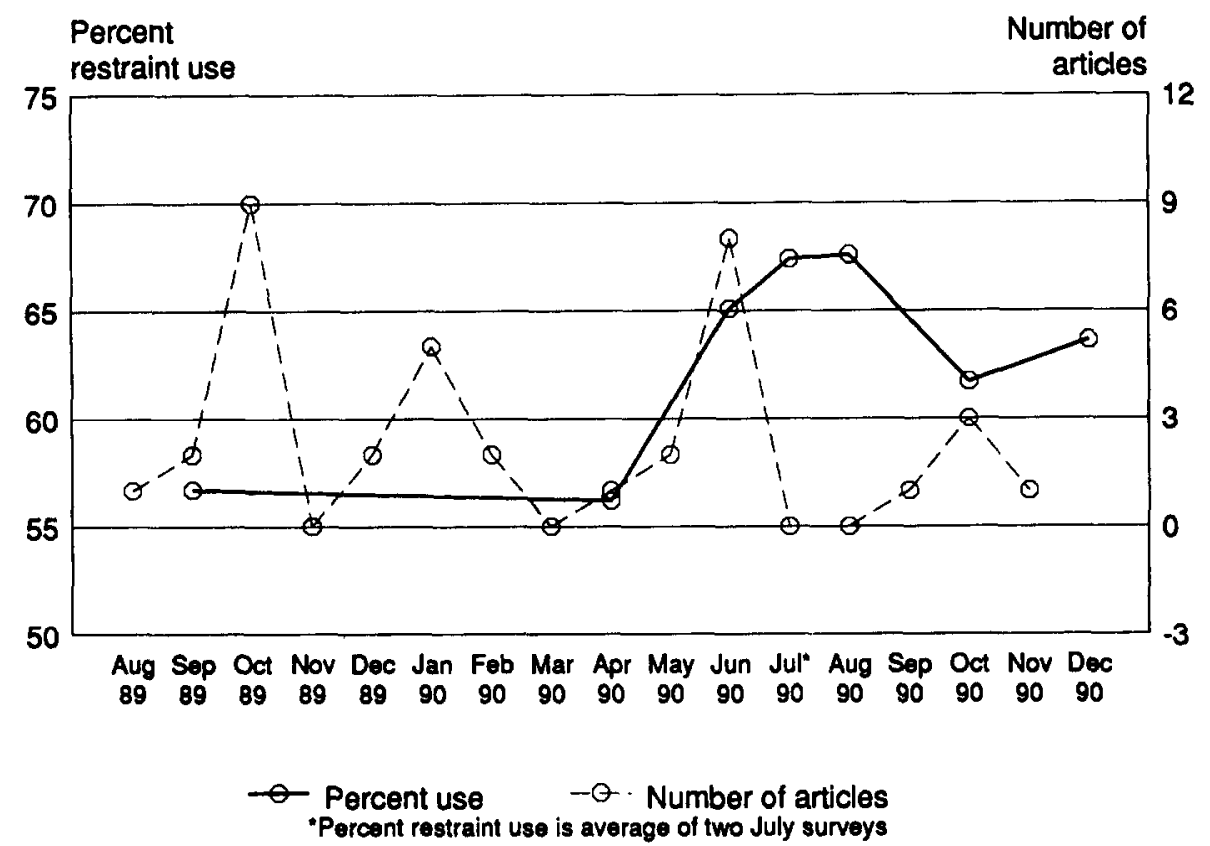

Fig. 9. Restraint use vs. number of articles. 


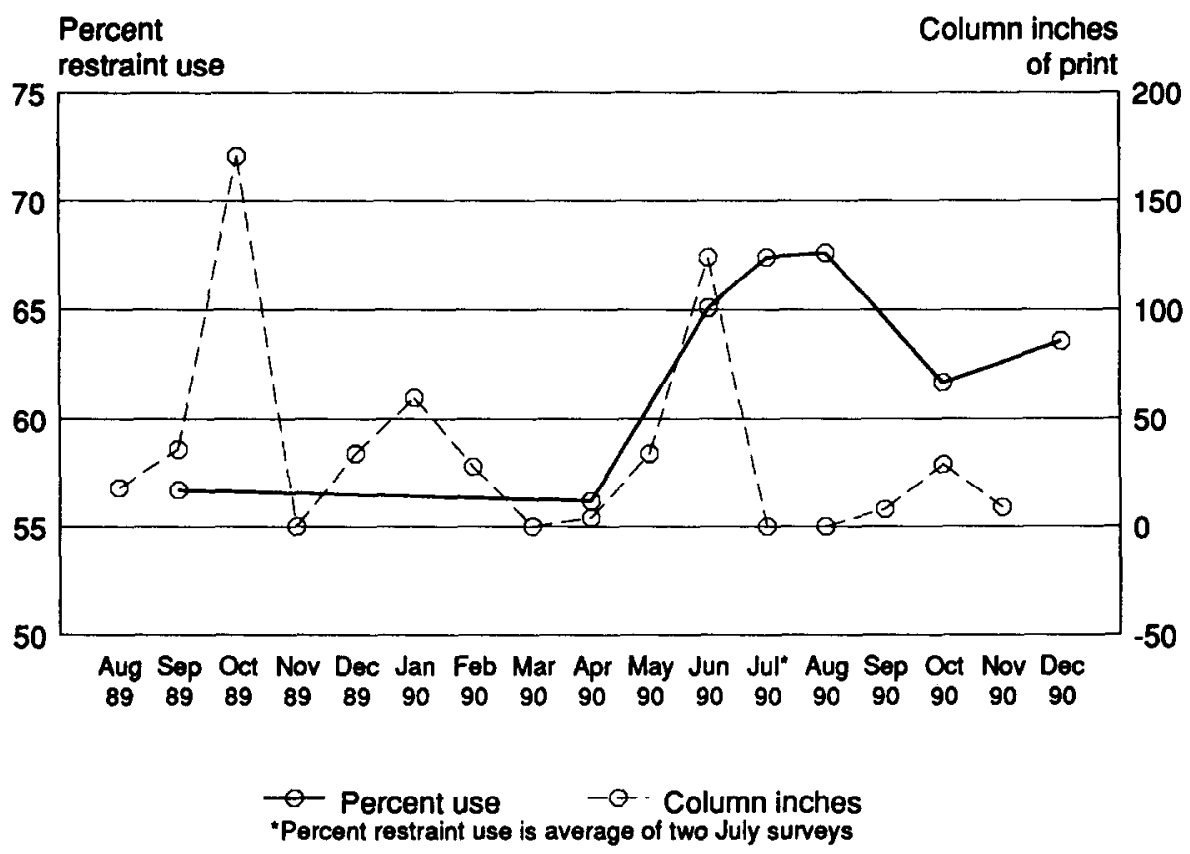

Fig. 10. Restraint use vs. column inches of print.

in restraint use followed. Unfortunately, our evaluation does not permit a specification of the amount of media attention that is necessary to support an enforcement program.

The lack of a systematic pattern between newspaper coverage and restraint use may be the result of an overly simplistic analysis. It is unlikely that restraint use will be changed by simply announcing or describing an enforcement program if the driving population does not perceive the enforcement program themselves (i.e. see police on the street). We therefore constructed charts depicting both patrol hours and restraint citations along with restraint use (Figs. 11 and 12). As was the case for newspaper

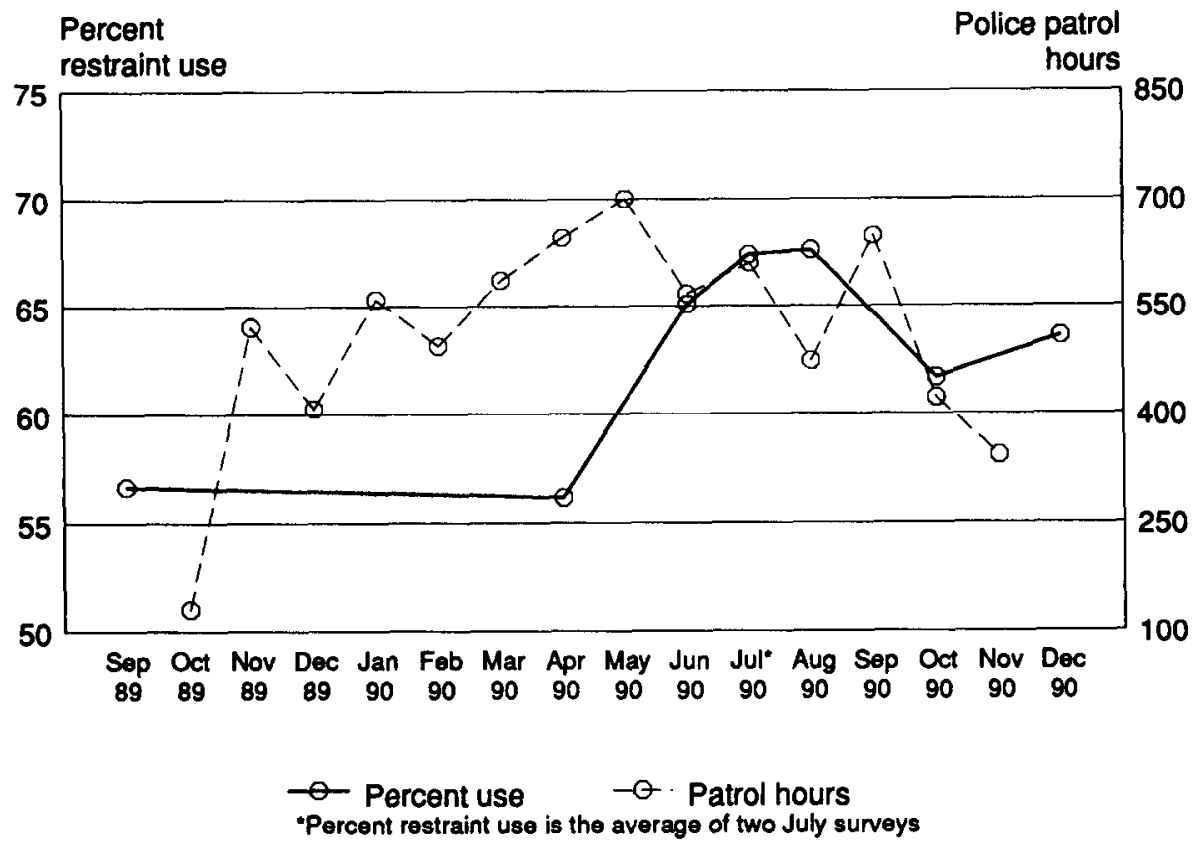

Fig. 11. Restraint use and patrol hours. 


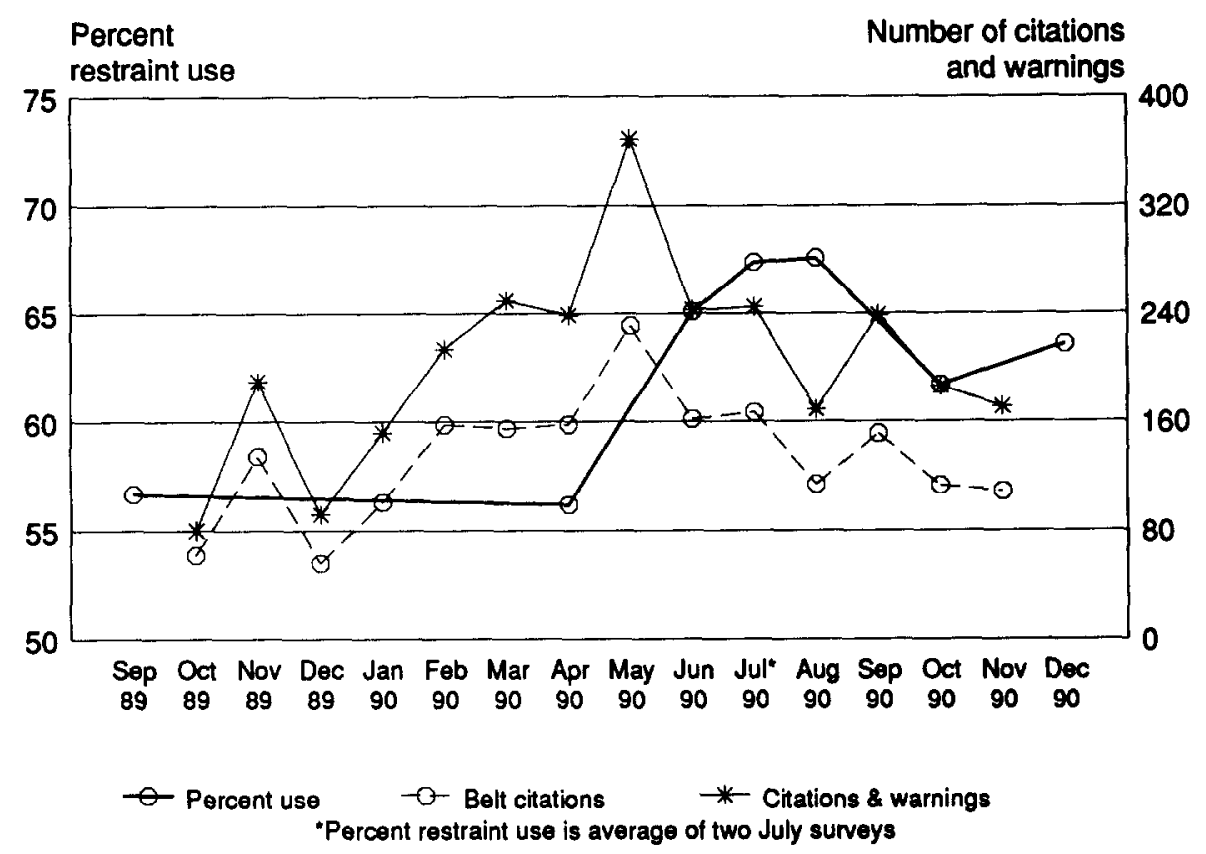

Fig. 12. Restraint use and restraint citations.

coverage, there is no apparent pattern to the relationships between either patrol hours or restraint citations and restraint use. However, newspaper coverage, patrol hours, and the number of restraint citations issued all peaked together around May and June 1990. This supports the assertion from Rood et al. (1987) that a combination of enforcement and media activity is essential for an effective program. It seems that both PI\&E and media coverage are necessary conditions for a successful program, but neither is sufficient by itself.

There is merit in examining the relationships between restraint use and police patrol activities with an evaluation plan permitting a more fine-tuned analysis. Such an evaluation could enable planners to better understand how resources need to be invested to have a successful program, and perhaps even what payoffs can be expected from a given investment in patrol and PI\&E efforts.

\section{CONCLUSIONS AND RECOMMENDATIONS}

The US-31 SAVE program designed to increase restraint use along the US-31 corridor was successful in achieving its behavioral goals. Restraint use increased significantly (8.4 percentage points from baseline levels) along the corridor due to the program. Although it dropped slightly when enforcement and PI\&E activity declined, belt use rates remained above baseline. While these results are promising, they show there is still much to be accomplished if we are to achieve belt use rates in the $75 \%-90 \%$ range.

The primary research need for PI\&E/enforcement programs to increase belt use is a better understanding of the minimum levels of activity necessary to achieve and maintain increases in restraint use. Such research should focus on increased understanding of the effects of media activity when combined with enforcement. Specifically, research is required to try to estimate a curve that would describe how much change in restraint use could be expected from specific levels of media and police patrol activity. This research should also examine what mix and timing of enforcement and media activity is necessary for behavior change. Although this program was designed to try to answer these questions, a research effort to pinpoint these levels will require greater resources than were available for this evaluation. There is also value in examining how the role of the enforcement/media mix is changed by different levels of baseline belt use. It is 
possible that we may never be able to achieve a fully satisfactory answer to the question of how much enforcement and/or media activity is enough to affect a prescribed level of behavior change, given the difficulties involved with controlling important variables in field research. However, this is a laudable goal and the information gleaned from such a program would prove valuable to program planners interested in promoting restraint use.

Acknowledgements - This study was supported by the National Highway Traffic Safety Administration and the Michigan Office of Highway Safety Planning. The opinions, findings, and conclusions expressed in this publication are those of the authors and not necessarily those of the Michigan Office of Highway Safety Planning nor the U.S. Department of Transportation, National Highway Traffic Safety Administration.

The contributions of several persons to the study reported here are appreciated: Laura Ratzlaff for her word processing and administrative assistance, Johannes (Joop) deLange for field data collection, and Robert Schultz for analysis of annual Michigan restraint observation data. A special thanks goes to Maggie Easterbrook, US-31 SAVE program monitor from the Michigan Office of Highway Safety Planning, and Blaine Koops, Holland Police Department, for coordinating and providing reports of US-31 SAVE enforcement activities. We also acknowledge the helpful suggestions from the editor and anonymous reviewers.

\section{REFERENCES}

Campbell, B. J. The Association between enforcement and seat belt use. J. Safety Res. 19:159-163; 1988.

Campbell, B. J.; Stewart, J. R.; Reinfurt, D. W. Change in injuries associated with safety belt laws. Accid. Anal. Prev. 23:87-93; 1991.

Datta, T. K.; Guzek, P. Restraint system use in 19 U.S. cities 1989 annual report. Washington, DC: U.S. Department of Transportation, National Highway Traffic Safety Administration; 1990.

Reinfurt, D. W.; Campbell, B. J.; Stewart, J. R.; Stutts, J. C. Evaluating the North Carolina safety belt wearing law. Accid. Anal. Prev. 22:197-210; 1990.

Rood, D. H.; Kraichy, P. O.; Carman, J. A. Selective traffic enforcement program for occupant restraints. Final report. Washington, DC: U.S. Department of Transportation, National Highway Traffic Safety Administration; 1987.

Streff, F. M.; Molnar, L. J. Direct observation of safety belt use in Michigan: Spring 1990. Ann Arbor, MI: The University of Michigan Transportation Research Institute; 1990.

Streff, F. M.; Wagenaar, A. C.; Schultz, R. H. Reductions in police-reported injuries associated with Michigan's safety belt law. J. Safety Res. 21:9-18; 1990.

Wagenaar, A. C.; Wiviott, M. B. T. Effects of mandating seatbelt use: A series of surveys on complicance in Michigan. Public Health Rep. 101(5):505-513; 1986.

Williams. A. F.; Preusser, D. F.; Blomberg, R. D.; Lund, A. K. Seat belt use law enforcement and publicity in Elmira, New York: A reminder campaign. Am. J. Public Health 77(11):1450-1451; 1987 